\title{
Tramadol or Nalbuphine; Which One is Superior for Analgesia in Post- Operative Period after Percutaneous Nephrolithotomy
}

\author{
Muhammad Sheraz Javed1, Ghulam Mehboob Subhani², Muhammad Akmal', Muhammad Irfan Munir4, \\ Safdar Hassan Javed ${ }^{5}$
}

Senior Registrar, Department of Urology, DHQ Hospital, Faisalabad Pakistan

1 Principal author, Principal investigator, Data collection $\mathcal{E}$ processing, Manuscript writing

Professor E Head, Department of Urology E Kidney Transplantation, Allied E DHQ Hospitals/Faisalabad Medical

2 University, Faisalabad Pakistan

Co-author

Assistant Professor, Department of Urology E Kidney Transplantation, Faisalabad Medical University, Faisalabad

3 Pakistan

Co-author

Assistant Professor, Department of Urology E Kidney Transplantation, Faisalabad Medical University, Faisalabad

4 Pakistan

Co-author

5 Professor $\mathcal{E}$ Head, Department of Urology, Independent Medical College, Faisalabad Pakistan

5 Co-author, Research supervisor

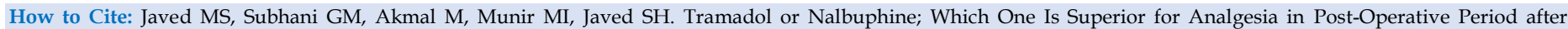
Percutaneous Nephrolithotomy. APMC 2021;15(1):51-4. DOI: 10.29054/APMC/2021.1062

\section{ABSTRACT}

Background: Kidney stones has got high prevalence worldwide especially in our part of world and per-cutaneous nephrolithotomy (PCNL) is gold standard operative modality for renal stone management. Pain control after PCNL is the most important task for treating surgeon as effective pain control causes smooth patient recovery in post-operative period. For analgesia, many drugs can be used, out of which tramadol and nalbuphine always been in comparison for effective analgesic activity. Objective: To compare efficacy of tramadol and nalbuphine as potent analgesic in patients after PCNL. Study Design: A prospective randomized study. Settings: Department of Urology and Kidney Transplantation, Allied Hospital/Faisalabad Medical University, Faisalabad and Department of Urology, DHQ Hospital/Faisalabad Medical University, Faisalabad Pakistan. Duration: From September 2016 to September 2020 (4 Years). Methodology: 286 patients undergoing PCNL for either gender and sides enrolled in study according to inclusion and exclusion criteria. Patients divided into Group A (Administered with tramadol) and Group B (administered with nalbuphine) and patients evaluated for pain up to 48 hours after surgery using 11-point numerical pain rating scale rating from $0-10$ where 0 is no pain, 1-3 mild pain, 4-6 moderate pain, 7-9 severe pain and 10 as worst pain and use of rescue analgesia observed in either groups. Data obtained and statistical evaluation done. Results: 286 patients enrolled from age 15-75 years with mean age of 40.2 years. Among 286 patients, 161 were male and 125 were female patients. Both groups A and B having 143 patients each. Analysis showed that tramadol has superiority over nalbuphine and need of analgesia is more in patient given nalbuphine (118 vs 31) as maintenance analgesic agent in post-operative period after PCNL. Conclusion: This study showed that tramadol has superiority over nalbuphine for analgesia after PCNL.

Keywords: Per-cutaneous nephrolithotomy, Tramadol, Nalbuphine.

\section{INTRODUCTION}

Nephrolithiasis is one of the most commonly presented illness being observed in urological facilities. ${ }^{1}$ Incidence of renal stone disease is increasing day by day globally ${ }^{2,3}$ especially in third world/under develop countries because of risk factors, traditional dietary habits and climate conditions. Although a national data is lacking to find out exact incidence of renal stones, it is roughly estimated that every third patient seeking medical attention in urological outdoor is patient with renal stone. ${ }^{4,5}$ Worldwide prevalence of renal stones is $10 \%$ in men and about $5 \%$ in women. ${ }^{6}$ There are variety of treatment options for renal stones depending upon size of stone, location of stone in renal pelvicalyceal system and patient body habitus. ${ }^{7}$ These treatment options have diversity from conservative management to small sized non obstructing stones, oral dissolution therapy for selected small stones, extra shock wave lithotripsy (ESWL) for stone sized about 1.5 to $2 \mathrm{~cm}$, and surgical modalities for resistant or hard or large stones. 7 These surgical modalities include, open pyelolithotomy, laparoscopic pyelolithotomy, robot assisted pyelolithotomy and per-cutaneous nephrolithotomy, where per-cutaneous nephrolithotomy (PCNL) being minimally invasive, endoscopic, procedure with least morbidities, is recognized as gold standard surgical treatment for renal stone. PCNL is first described and explained by Fernstrom and Johansson. ${ }^{8}$ PCNL is being 
performed in general anesthesia either in supine fashion or in prone fashion. Because of anatomical positioning of surgical techniques, post-operative pain control is of vital importance as lack of effective analgesia is associated with respiratory problems in patients undergoing PCNL in post-operative period. Debate has been in process in literature to find out ideal maintenance analgesic for such patients in post-operative period, still clinicians have not reached to consensus about ideal analgesic in postoperative period after PCNL. Most of debate revolves around intravenous use of tramadol and nalbuphine. Tramadol is an agent which has central mode of action. It is a synthetically prepared analgesic of opioid origin..$^{9}$ It is a non-selective agonist at delta, mu and kappa opioid receptors with a relatively higher affinity for the mu receptors. ${ }^{10}$ It has also action as a 5-HT2C receptor antagonist, antagonist to ( $\alpha 7) 5$ nicotinic acetylcholine receptor, NMDA receptor antagonist and as an antagonist to M1 and M3 muscarinic acetylcholine receptors. ${ }^{10}$ Tramadol can be given as oral preparation, intramuscular or intravenous route. Nalbuphine, a synthetic opioid agonist-antagonist analgesic which belongs to the phenanthrene series. ${ }^{11}$ It can be administered subcutaneously, intramuscularly or by intravenous route. It acts by binding to kappa,mu and delta receptors with prime affinity to kappa agonist and partial mu antagonist analgesic activity. ${ }^{11}$ Side effects of both agents are comparable with nalbuphine having more side effects related to nervous system.12,13 Pain assessment has been difficult to quantify especially in post-operative period and among these assessment tool, verbal tools have been considered as gold standard and among verbal tools, verbal rating scales (VRS), numerical rating scales (NRS) and visual analogue scales (VAS) are mostly used. Along with these tools, need of rescue analgesic agent is also a determinant for analyzing analgesia adequacy. Keeping in consideration about importance of a good analgesic agent, a study has been conducted to compare and find out a preferred analgesic agent among nalbuphine and tramadol so that post-operative recovery of patients undergoing PCNL can be made uneventful and by avoiding side effects of different other pharmacological agents.

\section{OBJECTIVE}

To compare efficacy of tramadol and nalbuphine as potent analgesic in patients after per-cutaneous nephrolithotomy.

\section{METHODOLOGY}

Study Design: Prospective randomized study.

Settings: Department of Urology and Kidney Transplantation, Allied Hospital/Faisalabad Medical University, Faisalabad and Department of Urology, DHQ Hospital/Faisalabad Medical University, Faisalabad Pakistan.
Duration: This study has been conducted between September 2016 to September 2020 (4 Years).

Sample Size \& Technique: 286 patients were enrolled using non probable consecutive sampling, randomized into two different groups by lottery method.

Inclusion Criteria: Patients undergoing PCNL included in this study were included according to following criteria.

1. Patients with renal stones of size more than $2 \mathrm{~cm}$

2. Patients with ESWL refractory renal stones of size less than $2 \mathrm{~cm}$

3. Patients of either genders

4. Renal stones of either literality (Both right sided and left sided renal stone)

5. Patients of age between 15-75 years

Exclusion Criteria: Patients excluded from the study according to following criteria.

1. Patients aged less than 15 years and more than 75 years.

2. Patients unfit for PCNL medically

3. Patients with BMI more than 30

4. Pregnant females

5. Patients with history of hypersensitivity to tramadol and nalbuphine.

6. Patients with nervous and cognitive disabilities.

7. Patients with musculoskeletal ailments of vertebral column and para spinal muscles.

8. Patients with previous history of open or endoscopic renal surgeries.

Data Collection Procedure: Patients enrolled according to inclusion and exclusion criteria. Patients have been evaluated in outdoor and admitted in indoor facilities at Department of Urology and Kidney Transplantation, allied Hospital/Faisalabad Medical University, Faisalabad and Department of Urology, DHQ Hospital/Faisalabad Medical University, Faisalabad. Patient have been evaluated by ultrasonography KUB, intravenous urography, CT scan KUB (in selected patients). All patients have been administered general anesthesia. Retrograde ureteric catheterization done in lithotomy position and prone position made in all patients. Ultrasound guided or fluoroscopic guidance renal puncture made using LP needle G 16 and tract made by seldinger technique. Tract dilated up to $30 \mathrm{FR}$ using coaxial metallic dilators. PCNL done using nephroscope while using pneumatic intra-corporeal lithotripters and stones fragments removed. Stone clearance achieved. Peri-tract injection bupivacaine (diluted preparation) 10 $\mathrm{ml}$ administered in all patients. Patient categorized in Group A (Patients who have been administered intravenous tramadol) in dosage $1 \mathrm{mg} / \mathrm{kg}$ in saline preparation in BD dose and Group B (Patients who have been administered intra-venous nalbuphine) in dosage of $0.2 \mathrm{mg} / \mathrm{kg}$ in saline preparation given BD. Rescue analgesia given in form of diclofenaic sodium $2 \mathrm{mg} / \mathrm{kg}$ intra-muscular administration in SOS. Patients evaluated for pain up to 48 hours after surgery using 11-point 
numerical pain rating scale rating from $0-10$ where 0 is no pain, 1-3 mild pain, 4-6 moderate pain, 7-9 severe pain and 10 as worst pain.

Statistical Tool: Data was obtained and stratified in terms of gender and age. Descriptive analysis was done and reported in terms of mean values and percentages. Continuous variables analysis was done using unpaired $t$ test and chi square test. Categorical variables analyzed using Fisher Exact Test. P $<0.05$ was taken as statistically significant. Statistical analysis done using SPSS version 23.

\section{RESULTS}

Total 286 patients enrolled in study between age group 15-75 years with mean age 40.2 years. Patients categorized into Group A and Group B with 143 patients in either group. Age stratification done as sub group 1, 2 and 3 with age limits as age between 15-35 years, 36-55 years and 56-75 years respectively and Group A distribution done in Group A-1, A-2, A-3 and Group B distribution done in Group B-1, B-2, B-3 and gender distribution in all groups done as shown in Table no. 1 .

Table 1: Gender distribution in Group A and Group B

\begin{tabular}{|c|c|c|c|c|c|c|c|c|}
\hline \multirow{2}{*}{ Gender } & \multicolumn{3}{|c|}{ Group A } & \multirow{2}{*}{$\begin{array}{c}\text { Grand } \\
\text { Total }\end{array}$} & \multicolumn{3}{|c|}{ Group B } & \multirow{2}{*}{$\begin{array}{c}\text { Grand } \\
\text { Total }\end{array}$} \\
\cline { 2 - 6 } & A-1 & A-2 & A-3 & & B-2 & B-3 & \\
\hline Male & 33 & 38 & 3 & 74 & 30 & 53 & 4 & 87 \\
\hline Female & 18 & 46 & 5 & 69 & 21 & 31 & 4 & 56 \\
\hline Total & 51 & 84 & 8 & 143 & 51 & 84 & 8 & 143 \\
\hline
\end{tabular}

Patients observed for pain in either group and data obtained for different grades of pain as criteria above and data for Group A and Group B elaborated as shown in Table 2 and Table 3 respectively.

Table 2: Grade of pain in Group A

\begin{tabular}{|c|c|c|c|c|c|c|c|}
\hline \multirow{3}{*}{$\begin{array}{c}\text { Pain } \\
\text { Character }\end{array}$} & \multicolumn{6}{|c|}{ Group A } & \multirow{3}{*}{ Tota } \\
\hline & \multicolumn{2}{|c|}{ Group A-1 } & \multicolumn{2}{|c|}{ Group A-2 } & \multicolumn{2}{|c|}{ Group A-3 } & \\
\hline & Male & Female & Male & Female & Male & Female & \\
\hline No Pain & 17 & 2 & 8 & 11 & 0 & 1 & 39 \\
\hline Mild Pain & 8 & 9 & 21 & 9 & 2 & 3 & 52 \\
\hline $\begin{array}{l}\text { Moderate } \\
\text { pain }\end{array}$ & 2 & 2 & 4 & 21 & 1 & 1 & 31 \\
\hline $\begin{array}{l}\text { Severe } \\
\text { Pain }\end{array}$ & 4 & 2 & 4 & 3 & 0 & 0 & 13 \\
\hline $\begin{array}{l}\text { Worst } \\
\text { Pain }\end{array}$ & 2 & 3 & 1 & 2 & 0 & 0 & 8 \\
\hline Total & 33 & 18 & 38 & 46 & 3 & 5 & 143 \\
\hline
\end{tabular}

Table 3: Grade of pain in Group B

\begin{tabular}{|c|c|c|c|c|c|c|c|}
\hline \multirow{3}{*}{$\begin{array}{c}\text { Pain } \\
\text { character }\end{array}$} & \multicolumn{6}{|c|}{ Group b } & \multirow{3}{*}{ Tota } \\
\hline & \multicolumn{2}{|c|}{ Group b-1 } & \multicolumn{2}{|c|}{ Group b-2 } & \multicolumn{2}{|c|}{ Group b-3 } & \\
\hline & Male & Female & Male & Female & Male & Female & \\
\hline No pain & 2 & 1 & 11 & 4 & 0 & 1 & 19 \\
\hline Mild pain & 5 & 11 & 4 & 2 & 0 & 0 & 22 \\
\hline $\begin{array}{c}\text { Moderate } \\
\text { pain }\end{array}$ & 11 & 2 & 9 & 21 & 1 & 1 & 45 \\
\hline $\begin{array}{c}\text { Severe } \\
\text { pain }\end{array}$ & 8 & 2 & 21 & 4 & 3 & 0 & 38 \\
\hline $\begin{array}{l}\text { Worst } \\
\text { pain }\end{array}$ & 4 & 5 & 8 & 0 & 0 & 2 & 19 \\
\hline Total & 30 & 21 & 53 & 31 & 4 & 4 & 143 \\
\hline
\end{tabular}

Need of rescue analgesic was needed in Group A in 31 patients out of 143 and in Group B, 118 patients have to had rescue analgesic out of 143 patients. Statistical analysis showed need of analgesia was statistically significant in group B patients and in Group A patients, need of rescue analgesia was statistically insignificant. Comparing both drugs, it has been found that tramadol has more potent analgesic effect as compared to nalbuphine in post-operative circumstances in patients after PCNL. Minor side effects of nausea and drowsiness was observed in Group B patients with no statistical significance. Mild nausea was observed in Group A patients with no statistical significance.

\section{DISCUSSION}

Patients of renal stones are increasing day by day and operative mode of treatment has been a mainstay treatment modality for such patients. Among operative techniques, per-cutaneous nephrolithotomy (PCNL) is considered to be gold standard. ${ }^{14}$ Although PCNL is associated with least number of complications, pain in post-operative circumstances is the main morbidity faced by patients. Pain is due to tear effect in muscles of corresponding area and stretch. Pain causes respiratory problems as sub costal position of tract and is associated with delayed post-operative recovery. ${ }^{15}$ So, use of appropriate analgesia is required to make patient postoperative recovery eventless. Discussion has been in progress about type of analgesia after any surgery in literature $^{16}$ and mainstay of discussion lies between tramadol and nalbuphine. According to a study, Kamath SS et al 2013, nalbuphine was found more potent analgesic as compared to tramadol. ${ }^{17}$ Same findings were observed by Siddiqui KM et al 2007, finding nalbuphine a superior choice of analgesia as compared to tramadol. ${ }^{18}$ Kaygusuz $\mathrm{K}$ et al 2007 compared tramadol and lornoxicam and found tramadol more potent. ${ }^{19}$ However few studies showed that need of rescue analgesia is comparable in either groups. ${ }^{20}$ But unfortunately, very little work has 
been done in our country in this regard to find out preferred analgesia. So, this study was designed and conducted with intention to find out preferred analgesia for our patients. According to this study, analgesic efficacy is superior in tramadol as compared to nalbuphine and this study also finds that need of rescue analgesia is more in patients administered with nalbuphine as compared to patients given tramadol as maintenance analgesic agent. However, both drugs can be used with comparable safety for patients in postoperative period after PCNL.

\section{CONCLUSION}

Based upon results obtained, this study concludes that tramadol has got superiority as compared nalbuphine for analgesia in patients after PCNL.

\section{LIMITATIONS}

This study is single institutional and has relatively small sample size.

\section{SUGGESTIONS / RECOMMENDATIONS}

It is suggested that multi-institutional study with a large sample size should be carried out and further modes and medications of analgesia available should be compared to find out the best analgesic for post-operative period after PCNL.

\section{CONFLICT OF INTEREST / DISCLOSURE}

There is no conflict of interest to be disclosed.

\section{ACKNOWLEDGEMENTS}

Efforts of whole department is acknowledged which helped for patient preparation for surgery and data collection after surgery regarding study.

\section{REFERENCES}

1. Sorokin I, Mamoulakis C, Miyazawa K, Rodgers A, Talati J, Lotan Y. Epidemiology of stone disease across the world. World J Urol. 2017;35(9):1301-20.

2. Scales CD, Smith AC, Hanley JM \& Saigal CS. Prevalence of kidney stones in the United States. Eur. Urol. 2012;62(1):160-5.

3. Thongprayoon C, Krambeck AE, Rule AD. Determining the true burden of kidney stone disease. Nat Rev Nephrol. 2020;16(12):73646.

4. Yasui T, Iguchi M, Suzuki S, Kohri K. Prevalence and epidemiological characteristics of urolithiasis in Japan: national trends between 1965 and 2005. Urology. 2008;71(2):209-13.

5. Lee YH, Huang WC, Tsai JY, Lu CM, Chen WC, Lee MH, et al. Epidemiological studies on the prevalence of upper urinary calculi in Taiwan. Urol Int. 2002;68(3):172-7.
6. Ranabir S, Baruah MP, Devi KR. Nephrolithiasis: Endocrine evaluation. Indian J Endocr Metab. 2012;16(2):228-35.

7. El-Nahas AR, El-Assmy AM, Awad BA, Elhalwagy SM, Elshal AM, Sheir KZ. Extracorporeal shockwave lithotripsy for renal stones in pediatric patients: a multivariate analysis model for estimating the stone-free probability. Int J Urol. 2013;20(12):1205-10.

8. Bill TH WONG. Percutaneous Nephrolithotomy. 2009;14(10):1417. http://www.fmshk.org/database/articles/04mb3_2.pdf

9. Raffa RB, Friderichs E, Reimann W, Shank RP, Codd EE, Vaught JL. Opioid and nonopioid components independently contribute to the mechanism of action of tramadol, an 'atypical' opioid analgesic. J Pharmacol Exp Ther. 1992;260(1):275-85.

10. Tricia E. Brentjens, David O. Warner; Pharmacology \& Physiology in Anesthetic Practice, 4th Edition.. Anesthesiology 2006; 105:864

11. Michel MS, Trojan L, Rassweiler JJ. Complications in percutaneous nephrolithotomy. Eur Urol. 2007;51(4):899-906.

12. Beakley BD, Kaye AM, Kaye AD. Tramadol, Pharmacology, Side Effects, and Serotonin Syndrome: A Review. Pain Physician. 2015;18(4):395-400.

13. Chou R, Gordon DB, de Leon-Casasola OA, Rosenberg JM, Bickler $S$, et al. Management of Postoperative Pain: A Clinical Practice Guideline from the American Pain Society, the American Society of Regional Anesthesia and Pain Medicine, and the American Society of Anesthesiologists' Committee on Regional Anesthesia, Executive Committee, and Administrative Council. J Pain. 2016;17(2):131-57.

14. Tsai SH, Chung HJ, Tseng PT, Wu YC, Tu YK, Hsu CW, et al. Comparison of the efficacy and safety of shockwave lithotripsy, retrograde intrarenal surgery, percutaneous nephrolithotomy, and minimally invasive percutaneous nephrolithotomy for lower-pole renal stones: A systematic review and network meta-analysis. Medicine (Baltimore). 2020;99(10):e19403.

15. Hatipoglu Z, Gulec E, Turktan M, Izol V, Arıdogan A, Gunes Y et al. Comparative study of ultrasound-guided paravertebral block versus intravenous tramadol for postoperative pain control in percutaneous nephrolithotomy. BMC Anesthesiol. 2018;18(1):24.

16. Capodice JL, Parkhomenko E, Tran TY, Thai J, Blum KA, Chandhoke RA, et al. A Randomized, Double-Blind, ShamControlled Study Assessing Electroacupuncture for the Management of Postoperative Pain after Percutaneous Nephrolithotomy. J Endourol. 2019;33(3):194-200.

17. Kamath SS, Kumar BC, Upadya M, Bhat S. A comparison of the analgesic effect of intravenous nalbuphine and tramadol in patients with post-operative pain-a double blind prospective randomised study. Asian J Pharm Health Sci. 2013;3(3):786-90

18. Siddiqui KM, Chohan U. Tramadol versus nalbuphine in total intravenous anaesthesia for dilatation and evacuation. J Pak Med Assoc. 2007;57(2):67-70.

19. Kaygusuz K, Gokce G, Ozdemir Kol I, Ayan S, Gursoy S. Efficacy of preventive analgesia with tramadol or lornoxicam for percutaneous nephrolithotomy: a prospective, randomized, double-blind, placebo-controlled study. Curr Ther Res Clin Exp. 2007;68(4):205-16.

20. Moyao-García D, Hernández-Palacios JC, Ramírez-Mora JC, NavaOcampo AA. A pilot study of nalbuphine versus tramadol administered through continuous intravenous infusion for postoperative pain control in children. Acta Biomed. 2009;80(2):124-30. 